\title{
Methodological approaches used to assess the relationship between parental supervision and child injury risk
}

\author{
L A Petrass, C F Finch, J D Blitvich
}

\begin{abstract}
Objective: To describe and rate the quality of methodological approaches used to measure parental supervision in relation to injury risk in children aged 0-14 years.
\end{abstract}

Design: A systematic review of the literature related to supervision and injury risk.

Methods: A comprehensive search of electronic databases from the earliest records available to the end of 2007, and supplemental hand-searching of relevant journals, reference lists of studies identified through database searches, and bibliographies of systematic and non-systematic reviews. A classification scale was used to rate the methodological quality of studies.

Results: 30 papers met the inclusion criteria. They varied substantially in quality, and no meta-analyses or randomised controlled trials were identified. Fifteen studies used self-report approaches, asking parents or care givers to report through recording diaries, interviews and questionnaires and were considered of low quality; 11 studies reconstructed injury outcomes retrospectively. Observational studies were conducted in both laboratory and natural settings $(n=6)$, and these studies were generally of higher quality than self-report methods.

Conclusions: The quality of many supervision and child injury risk studies is low to moderate. Further development of methodological approaches is needed to improve studies of the relationship between supervision and child injury risk.

Unintentional injuries pose a serious health threat to children, with young children particularly vulnerable to injuries that occur in and around the home. ${ }^{13}$ Across the developed world, uninten tional injury is the leading cause of hospitalisation and death for children, ${ }^{46}$ and many children survive their injuries, with a lifetime of physical, emotional and socioeconomic consequences. Further empirical research and prevention pro grammes must target children because of these implications.

A lapse in, or lack of, parental supervision has been associated with unintentional injuries and death from drownings and near drownings, pedes trian injuries and falls in children aged 014 years. ${ }^{7}$ Studies measuring parental supervision have drawn conclusions about the implications that the level of supervision has for child injury risk using self report or mixed methods.. ${ }^{80}$ Other studies have examined the behaviour of injured and uninjured children and the supervisory prac tices of their parents in a contrived hazard setting. ${ }^{11}{ }^{12}$ Unfortunately, many studies have made inferences about the importance of parental supervision without actually measuring it. ${ }^{13}{ }^{18} \mathrm{Few}$ studies have directly related supervision to child injury risk, despite the individual and societal burdens associated with unintentional injury as a leading childhood health problem. ${ }^{1}{ }^{2}$

Although methodological and conceptual issues related to care giver supervision and its role in childhood injury have been addressed in literature reviews, ${ }^{71}$ the range of study methods and approaches used to investigate supervision and childhood injury risk have not previously been systematically and comprehensively examined. There is no standardised measure of the relation ship between supervision and children's injuries, ${ }^{20}$ and there are significant challenges in developing and implementing such a measure. ${ }^{79}$ It has recently been argued that systematic reviews of the methods used in studies of injury and super vision are required. ${ }^{21}$

This systematic review addresses this informa tion. It describes the methodologies used in studies of supervision and injuries or injury risk in young children, and highlights the advantages and dis advantages of different study methods. Quality research designs are identified which, should they be adopted in future studies, have the potential to provide a comprehensive understanding of super vision and its role in preventing unintentional childhood injuries. It is beyond the scope of this paper to describe the actual findings from the reviewed studies.

\section{METHODS}

\section{Inclusion and exclusion criteria}

Studies were included in this systematic review if they met all of the following criteria: (1) explained aspects of supervision and/or evaluated the effec tiveness of supervision using an outcome measure (irrespective of the definition of supervision); (2) targeted children aged 014 years; (3) reported on any form of supervision provided by parents/care givers, guardians or siblings to prevent uninten tional injuries to children; (4) included a primary outcome measure of injury risk and/or injury incidence. Identified studies included investiga tions of public recreational child play settings and aquatic environments, self reported or medically attended unintentional injury, and care giver safety practices.

Studies in formal settings (eg, crèche, child care, school) were excluded as parents or guardians were not responsible for providing supervision in these settings. Studies of supervisory neglect were 
Table 1 Classification scale for assessing the quality of the methodological approaches used in studies of supervision and child injury and injury risk

\begin{tabular}{|c|c|c|c|}
\hline $\begin{array}{l}\text { Type of methodological } \\
\text { approach }\end{array}$ & $\begin{array}{l}\text { Number of } \\
\text { studies }\end{array}$ & Settings & References \\
\hline $\begin{array}{l}\text { Self report (including } \\
\text { questionnaires, interviews and } \\
\text { injury recording diaries) }\end{array}$ & 15 & $\begin{array}{l}\text { Aquatic } \\
\text { Home } \\
\text { Pedestrian } \\
\text { Playgrounds }\end{array}$ & $\begin{array}{l}3,9,10,27 \\
3039,45\end{array}$ \\
\hline $\begin{array}{l}\text { Reconstruction studies of injury } \\
\text { outcomes (including field } \\
\text { investigation of injury sites, } \\
\text { causal sequence } \\
\text { reconstruction, and case series } \\
\text { review studies) }\end{array}$ & 11 & $\begin{array}{l}\text { Aquatic } \\
\text { Pedestrian } \\
\text { Home }\end{array}$ & $\begin{array}{l}32,33,4044, \\
4648,52\end{array}$ \\
\hline $\begin{array}{l}\text { Observational studies of } \\
\text { behaviours in laboratory based } \\
\text { settings }\end{array}$ & 2 & Home & 11,12 \\
\hline $\begin{array}{l}\text { Observational studies of } \\
\text { behaviours in natural settings }\end{array}$ & 4 & $\begin{array}{l}\text { Playgrounds } \\
\text { Supermarkets }\end{array}$ & $8,9,50,51$ \\
\hline $\begin{array}{l}\text { Observational studies of } \\
\text { interventions (including } \\
\text { laboratory based and studies in } \\
\text { natural settings) }\end{array}$ & 2 & $\begin{array}{l}\text { Home } \\
\text { Supermarkets }\end{array}$ & 31,49 \\
\hline $\begin{array}{l}\text { Prospective non randomised } \\
\text { control (including case control } \\
\text { and cohort studies) }\end{array}$ & 0 & & \\
\hline Randomised controlled studies & 0 & & \\
\hline $\begin{array}{l}\text { Meta analyses: Cochrane } \\
\text { Reviews }\end{array}$ & 0 & & \\
\hline
\end{tabular}

The strength of the methodological review increases from self report (the least robust) to meta analyses (the most robust).

excluded because the point at which absence of adequate supervision is classified as neglect is often inconsistent and unclear. ${ }^{19}$ Studies of child poisonings and burns were also excluded because such injuries are primarily addressed via non supervisory strategies such as removal, controlled use and redesign of products. ${ }^{22} 23$

\section{Identification of studies}

Academic Search Premier, AUSPORT, AUSPORTMed, CINAHL, Cochrane Database of Systematic Reviews, ERIC, Health Source Consumer, Health Source Nursing, PsycINFO, PubMed, SafetyLit, Scopus, SPORTDiscus, Springer Link and Web of Science databases were searched for potentially relevant studies. Multiple databases were selected because of the growth in journals publishing studies relevant to injury prevention and safety promotion. ${ }^{24}$ Although English language search terms were used, all databases were searched for all languages, and from the earliest records available (range 1800 (The Cochrane Library) to 1989 (AUSPORT and AUSPORTMed)) until the end of December 2007. No foreign language studies were identified. Electronic searching was supplemented by hand searching of relevant journals, reference lists of identified studies and bibliographies of systematic and non systematic reviews.

In order to ensure that all relevant journal articles about injury and supervision were identified, a large number of search keywords and synonyms were adopted, ${ }^{25}{ }^{26}$ and the article title was broken down into individual concepts and components to ensure that the search was retrieving crucial studies. ${ }^{26}$ Where possible, the shortened forms of textwords were used so that both singular and plural forms were included in search findings.

The search terms "injury prevention" or "unintentional injury" or "injury risk", in conjunction with "parent", "guardian" or "carer" and "supervision", were used. "Supervision" was further combined with "infant" or "child" or "toddler" or "young children". "Parent", "guardian" or "carer" supervision was searched, and then used in juxtaposi tion with "accident", "near miss" and "near accident". The derivatives of applicable terms (eg, child, children) were incorporated.

Supervision in aquatic and active child play environments was of particular interest because of the diverse levels of risk and potential for injury in different settings, and the relative levels of supervision required to prevent injury. ${ }^{27}$ Therefore, after initial searches, the above search terms were combined separately with "aquatic", "water", "pool", "beach", "lake", "river" "drowning" and "near drowning", "play environment", "playground" and "pedestrian" terms.

Studies identified with this search strategy were screened by the first author (a $\mathrm{PhD}$ student), who examined study titles, abstracts and keywords. Obvious exclusions were removed, and the full texts of potentially relevant studies were obtained and assessed against the inclusion criteria to determine the appro priateness of each study. Uncertainties about appropriateness of studies for inclusion were resolved by consensus with coau thors. Classification of the studies was agreed to by all authors including a biostatistician/epidemiologist (CFF) and exercise scientist (JB), who both had experience in the conduct of injury studies.

\section{Quality assessment}

A methodological quality rating scale assessing common study designs in public and clinical health issues was identified. ${ }^{28}$ To reflect a public health approach, a classification scale for supervision studies was derived from this. Construct validity was established, as the classification was based on the National Health and Medical Research Council levels of evidence ${ }^{28}$ and a previous classification of injury studies. ${ }^{29}$ This scale allowed the methodological quality of the studies to be critically analysed and classified according to capacity to eliminate or minimise bias (table 1).

\section{RESULTS}

Screening of the study titles, abstracts and keywords identified 112 potentially relevant citations. After screening of the full text, 30 studies met all inclusion criteria. Four studies used a mixed method research approach, ${ }^{30}{ }^{33}$ and these studies are listed under both types of evidence in table 1 . Thirteen studies were conducted in the home,, 101230313440 eight in aquatic environments, ${ }^{41}{ }^{48}$ four in supermarkets, ${ }^{84} 51$ two in pedestrian settings, ${ }^{32}{ }^{33}$ and one in a playground environment. ${ }^{9}$ Two were general injury studies. ${ }^{27}{ }^{52}$ Studies that did not meet inclusion criteria were eliminated largely because no level of parental or care giver supervision was discussed or the effectiveness of supervision was not evaluated against an outcome based measure.

The context, method and duration of studies influenced their sample size, the number of children and supervisors in the included studies ranging from $19^{11}$ to $390 .^{8}$ The heterogeneity in design and context makes it difficult to compare across studies, but the sampling of children and supervisors is often identified as a limiting factor by authors. ${ }^{10} 27353839$ For example, although the findings of most studies may be representative of the population in which they were conducted, they cannot be generalised to other communities because of sample selection biases, such as socioeconomic and parental employment status and parental interest in the research area. Many stu $\operatorname{dies}^{3} 8273233363839454951$ adjusted or assessed for confounding 
Table 2 Validity and reliability of surveys used to investigate supervision and injury risk in children

\begin{tabular}{|c|c|c|c|c|}
\hline Questionnaire name & Description & Validity & Reliability & Studies \\
\hline The Injury Behaviour Checklist (IBC) & $\begin{array}{l}24 \text { items, measure of children's risk taking } \\
\text { and minor injuries }\end{array}$ & $\begin{array}{l}\text { Good convergent and construct } \\
\text { validity }\end{array}$ & $\begin{array}{l}\text { One month test retest reliability } \\
(0.81) \text {. Internal consistency very } \\
\text { good }(\alpha=0.87)^{56}\end{array}$ & $9,38,56^{*}$ \\
\hline $\begin{array}{l}\text { The Injury History Questionnaire } \\
\text { (IHO) }\end{array}$ & $\begin{array}{l}\text { Index of the frequency of minor injuries a } \\
\text { child has sustained in previous } 6 \text { months }\end{array}$ & Not reported & Not reported & $3,12,30,34,38$ \\
\hline $\begin{array}{l}\text { The Beliefs about Supervision } \\
\text { Questionnaire (BAS) }\end{array}$ & $\begin{array}{l}\text { Measures of parental supervision across } \\
\text { common child play areas }\end{array}$ & Not reported & $\begin{array}{l}\text { Internal consistency adequate for } \\
\text { judgements about child being left } \\
\text { alone }(0.68) \text { and good for child } \\
\text { receiving minimal supervision } \\
(0.72)^{38}\end{array}$ & 30,38 \\
\hline $\begin{array}{l}\text { Parent Supervision Attributes Profile } \\
\text { Questionnaire (PSAPQ) }\end{array}$ & $\begin{array}{l}\text { Measure of supervisory styles, parental } \\
\text { beliefs and attitudes }\end{array}$ & $\begin{array}{l}\text { Construct validity, with good } \\
\text { discriminate and convergent } \\
\text { validity of subscales }{ }^{20}\end{array}$ & $\begin{array}{l}\text { One month test retest reliability } \\
\text { acceptable for all factors (range } \\
0.720 .80 \text { ). Internal consistency } \\
\text { good (range } \alpha=0.77 \quad \alpha=0.79)^{20}\end{array}$ & $9,20 *$ \\
\hline $\begin{array}{l}\text { The Parent Protectiveness Scale } \\
\text { (PPS) }\end{array}$ & $\begin{array}{l}25 \text { items, measure of parental protection } \\
\text { behaviours for children aged } 2 \text { through } 10 \\
\text { years }\end{array}$ & Good criterion validity ${ }^{57}$ & $\begin{array}{l}\text { Test retest reliability over } 35 \\
\text { week interval good }(0.86) \text {. Internal } \\
\text { consistency good }(\alpha=0.73)^{57}\end{array}$ & $3,34,57^{*}$ \\
\hline The Supervision Rules Questionnaire & $\begin{array}{l}\text { Measure of supervision that an average child } \\
\text { requires, reporting time a child could be left } \\
\text { unsupervised }\end{array}$ & Not reported & Not reported & $27^{*}$ \\
\hline $\begin{array}{l}\text { Memory for hazards in waiting room } \\
\text { and degree of worry about these } \\
\text { items questionnaire }\end{array}$ & $\begin{array}{l}24 \text { items to assess what parents believed } \\
\text { had potential to cause injury to child while in } \\
\text { waiting room }\end{array}$ & Not reported & Not reported & 12 \\
\hline None given & $\begin{array}{l}24 \text { items, measures supervision practices } \\
\text { and parental perception of injury in the home }\end{array}$ & Not reported & Not reported & $10^{*}$ \\
\hline Home Safety Questionnaire & $\begin{array}{l}33 \text { items, identifies home safety rules and } \\
\text { reasons for not having rules about safety } \\
\text { hazards }\end{array}$ & Not reported & Not reported & $34^{*}$ \\
\hline None given & $\begin{array}{l}17 \text { items relating to bathtub supervision and } \\
\text { general demographics }\end{array}$ & Not reported & Not reported & $45^{*}$ \\
\hline
\end{tabular}

*Indicates studies that describe the development of the questionnaire measure.

factors, including child and supervisor characteristics such as gender and age, at the design or analysis phase. Assessment of potential confounders is imperative, as inadequate assessment can damage the strength of findings/results, threatening the validity of causal inferences drawn from the data. ${ }^{53}$

Owing to the relative infancy of supervision research, the methods reported in the studies varied substantially (table 1). The identified methods, as well as their associated advantages and shortcomings, are presented in the following paragraphs. They are presented in the order that they appear in table 1 according to their quality, from least to most robust. ${ }^{29}$

Self report was the most common data collection method and was implemented through interviews, questionnaires or parent recorded diaries. A number of studies required participants to self report on hypothetical scenarios, ${ }^{10}{ }^{27} 35$ report their individual supervisory behaviours in specific contexts (also referred to as participant event monitoring), ${ }^{3} 323739$ or complete questionnaires about their supervision and attitudes toward supervi sion. ${ }^{3} 91012202730343845$ The results of self report studies must be considered with care, as they rely on individuals reporting their own behaviours, and response bias is of concern. ${ }^{54}$ Table 1 shows that about half of identified studies were of this type.

A range of survey instruments were used across studies adopting the self report approach, and some surveys were used in more than one study. The quality of surveys is usually assessed through documented validity and reliability and, where this information was available, it is indicated in table 2. A number of non injury/supervision specific surveys (eg, The Family Information Questionnaire, Big Five Inventory and Parent Health Locus of Control) were also used. ${ }^{3} 303855$ However, as their focus is beyond the direct measurement of supervision and injury risk, they are not included in table 2.
Ideally, studies should use validated and reliable surveys so as not to undermine the value of the data collected.

Reconstruction studies of the incidents leading to injury outcomes and their causal factors obtained through case series reviews have often been used to understand parental super vision in aquatic settings. ${ }^{41} 446648$ Such studies can suggest when absent or inadequate supervision was a contributing factor in child drowning and near drowning incidents. As the informa tion is generally collected retrospectively, recall bias and observation of the scene after the incident mean that causal relationships cannot be firmly established. These studies are also limited when information on injuries or key events is missing. ${ }^{58}$

Observational studies overcome some of the biases inherent in the above methodologies. In laboratory settings, ${ }^{11}{ }^{12}$ observa tional study methods are often called contrived hazards because of the controlling of the child's exposure to risk. Such studies involve creating a naturally appearing situation, with naturally emerging hazards (that have been modified to eliminate the risk of injury) in a controlled environment. Examples include mothers and toddlers being unobtrusively observed and videotaped while they wait in a simulated office ${ }^{12}$ or playroom setting. ${ }^{11}$

A number of studies led by Harrell ${ }^{49} 5159$ have undertaken "natural observations" of children and their supervisors in the supermarket setting. As table 1 shows, this approach provides higher quality evidence than contrived hazard methods, because it occurs in an uncontrolled natural setting with minimal disturbance, influence or intrusion on the participants' beha viours through the observation process. ${ }^{60}$

Unfortunately, observational studies of interventions relating to supervision are rare to date, with only two studies identified, conducted in the home and supermarket. ${ }^{3149}$ No prospective 
non randomised controls, randomised controlled trials (RCTs) or meta analysis studies were found.

Many studies 930343639 have adopted mixed method approaches. Such studies can provide a more thorough analysis of injury risk and supervision than would be available from single method studies. ${ }^{38}{ }^{39}$ However, the quality of evidence is only as high as the best method implemented, unless triangula tion is conducted. Triangulation involves the use and compar ison of several different research methods to explore the same phenomenon, and is advantageous as it provides the researcher with a much more rounded picture of what is being studied. ${ }^{61}{ }^{62}$ Unfortunately, most of the mixed method studies in this systematic review did not take advantage of the potential to compare or overlap data to validate and confirm data obtained by various methods.

\section{DISCUSSION}

This systematic review has highlighted that self report, obser vational (in laboratories or natural settings) and case series methods are the most commonly used in child supervision and injury studies. Accordingly, the quality of the information obtained from the studies varied. Very few studies provided robust evidence of the extent to which injury risk is associated with levels of supervision. No RCTs were identified, and, although this design is considered to provide the best evidence, ${ }^{58}{ }^{63}$ it is likely to be unfeasible in this context because of the ethical difficulty of manipulating supervision levels and children's exposure to hazards. ${ }^{58}$ Further, as the primary outcome of interest (ie, injury) is rare in some contexts, ${ }^{58}$ RCTs may be prohibitively expensive.

Meta analyses provide a synthesis of studies with overall effect sizes quantified. ${ }^{64}$ Although stronger conclusions can be drawn, as the findings emerge after synthesis and evaluation of the relationship among results from many individual studies, ${ }^{65}$ no meta analyses were identified. Meta analysis requires empirical quantitative data rather than theoretical contribu tions or qualitative data; findings need to be configured in a comparable statistical form, and the same or similar constructs examined. ${ }^{65}$ Investigation of the same construct is problematic in new areas of research with a limited number of published peer reviewed studies.

Questionnaires are one of the most common self report research methodologies used, ${ }^{64}$ with participants asked to report opinions, attitudes, behaviours or beliefs, background and demographic information, and knowledge of intentions and aspirations. ${ }^{66}$ As a data collection tool, they are versatile, simple and relatively low cost for gathering a large amount of data of high enough quality to test hypotheses and make real world policy suggestions. ${ }^{53}$ However, a low response rate is often identified, ${ }^{65}$ and can vary according to the method of adminis tration. ${ }^{6}$ A low response rate has been identified as the major factor leading to response bias. Where possible, a researcher needs to demonstrate an absence of response bias, with the sample of respondents who return the questionnaire represen tative of the population. ${ }^{65}$

Few studies indicated whether their injury or supervision questionnaire had good reliability and validity. ${ }^{3} 90385657$ None gave extensive consideration to the problems associated with using measures with unknown reliability or validity. This is an issue because unvalidated instruments may not measure what they claim to measure, and it is not possible to determine the consistency of responses obtained through them. ${ }^{54}$ Further empirical research is needed to determine the validity and reliability of key measures of supervision, child injury or risk taking before the continued use of such measures in this area.

Questionnaires and interviews both obtain self report infor mation but with a different method of questioning. Both rely on participants willingly and accurately providing answers to posed questions. ${ }^{53}$ Validity of interview data can be established through comparison with other methods, and recording bias can be overcome by implementing a mechanical recording method such as audio or video recording. ${ }^{53}$ There is generally a higher response rate for interviews than written question naires. ${ }^{64}$ However, interviews are generally more expensive and require more time to collect and transcribe data. ${ }^{65}$

Although not common, information on supervisory beha viour in hypothetical situations is generally collected through interviews ${ }^{35}$ or questionnaires, ${ }^{10}{ }^{27}$ where supervisors report their expected behaviours in various hypothetical settings. Morrongiello ${ }^{7}$ has urged caution in interpreting findings from such studies because the data may not represent actual parental supervision, especially if parents have limited real world experience around which to base their judgements of behaviour in hypothetical situations. ${ }^{37}$ Consequently, the findings are not transferable to understanding how individuals supervise under natural conditions, because of insufficient ecological validity. Further, whether parents/carers' self reported beliefs in hypothetical situations align with their actual supervisory behaviour has not been determined. ${ }^{7}$

Diary recording of supervisory behaviour and children's injuries combined with interviews and questionnaires is one example of a mixed method approach to provide more detailed information as part of a triangulation process. ${ }^{53}$ Diaries in which participants have reported on supervision have gathered a wide range of information, including reports of thoughts, feelings and behaviours, and accounts of physical and social activity. The time period over which the diary is maintained has ranged from hours to a number of years, ${ }^{53}$ with entries varying between continuous diary recordings of supervision ${ }^{36} 3955$ and periodic recordings each time a child experienced an injury. ${ }^{38}$ This method is very cost effective and useful for investigating supervision behaviour if data from the same person are required frequently or over a considerable time frame, and yields information that is sequentially ordered. Theoretically, a diary method does not suffer from recall bias unless it is completed well after the event. However, it is not possible to assess whether or not a participant completes the diary honestly and in a timely manner. For these reasons, diaries are best used in conjunction with other methods that can indicate any discrepancies in self records. ${ }^{53} 67$

An interesting side effect of using diaries is that they can act as an intervention in themselves, ${ }^{53}$ in that recording specific behaviours can alter the likelihood and degree to which the participant engages in that behaviour. This can be overcome by adding an observational component to the study, to validate the diary recordings. However, continuous diary recording is extremely time consuming and laborious, often resulting in small sample sizes and a large dropout rate. ${ }^{37}$

Self reporting of supervisory behaviours (also referred to as participant event monitoring) often involves implementing a mixed method approach to understand how supervision relates to child injury risk. ${ }^{32} 3739$ Self reporting of actual supervision practices potentially provides more meaningful data than participants reporting on hypothetical situations. However, there is no way of knowing if parents alter their "normal" supervisory behaviour as a result of a study, and any alteration from their typical behaviour would directly influence study findings. ${ }^{38}$ 


\section{What is already known on this topic}

- Unintentional injury is the leading cause of hospitalisation and death for children across the developed world. A lack of, or inadequate, supervision has been implicated as a possible risk factor for these injuries.

- A number of research approaches have been used to investigate supervision and childhood injury risk.

\section{What this study adds}

- A classification scale to rank quality of methodological approaches has identified that most of the evidence about the relationship between supervision and the risk of injury to children aged $0-14$ years is only low-moderate, with no randomised controlled trials or meta-analyses reported.

- A number of studies have used mixed-method approaches to explore supervision, but, without triangulation, the full benefit of this approach is yet to be realised.

- There is an obvious need for further supervision research with better data-collection methods. In particular, a mixed-method approach is recommended to confirm and characterise the risk relationship between supervision and injury in children.

Case series methods (where reports such as coroners' findings are investigated) have been used in reconstruction studies of injury outcome to determine mechanisms of fatal injury and patterns of trauma care. ${ }^{58}$ They have been commonly used in aquatic settings to examine the relationship between drowning or near drowning incidents and their contributing factors, ${ }^{41} 444648$ because they allow data collection after the incident, resulting in understanding and confirmation of factors contributing to the event.

Coronial information, including police reports, post mortem reports, photographs and coroner's findings, provides highly detailed data about injury deaths. ${ }^{41}$ In developed countries, with a well established coronial system, it is unlikely that cases are missed when coronial records are used. ${ }^{41}{ }^{47}$ In this review, studies examining coronial information were conducted in the $\mathrm{USA}^{32}{ }^{33} 44_{48}{ }^{52}$ Australia $^{41446}$ and UK, ${ }^{47}$ and therefore it is unlikely that injury deaths were overlooked. Although provid ing a wealth of information, a disadvantage of such case series methods is that monitoring of cases takes a long time, as a number of organisations and groups need to be contacted to obtain all relevant information regarding the incident. Furthermore, important details about the injury event and levels of supervision may not be thoroughly documented on death certificates or medical records. For example, in the USA, information about pool fencing was lacking in drowning incident reports. ${ }^{68}$ This was not a concern in this review, as studies had to explain aspects of supervision and/or evaluate the effectiveness of supervision using a primary outcome measure of injury risk and/or incidence to be included.

A contrived hazard method may be advantageous in some areas of research, but because human behaviours are difficult to replicate ${ }^{69}$ it is physically impossible to construct all environ ments in a laboratory setting. In early studies using this method, parents potentially supervised in a self conscious or socially desirable manner, as they were aware that their behaviours were being monitored and understood that the hazards posed no threat of injury to children. ${ }^{11}$ A later study, incorporating a larger sample of supervisors who believed hazards were real and who were unaware their behaviours were being monitored, provides more ecologically valid results. ${ }^{12}$ Nonetheless, the contrived hazard method provides some information on parental supervisory behaviours and the interaction between parent and child behaviours without the influence of prior parental knowledge of data collection. A disadvantage of the contrived hazard method is that once participants are informed and familiar with the study, the method is no longer applicable, precluding longitudinal studies, which are required to determine if a relationship exists between supervision and child developmental stages. ${ }^{19}$ The level of parental supervision provided to young children is likely to vary depending on the situation or setting. There is a difficulty associated with constructing all environments and modifying hazards to appear real while posing no risk of injury to participants. ${ }^{12}$

Naturalistic observation is costly, time consuming and very labour intensive. ${ }^{9}$ However, it occurs in a natural setting and participants can be unaware that they are being observed, ${ }^{66}$ and therefore the observed behaviour is more likely to reflect the true supervisory behaviour. ${ }^{50}$ This method, adopted in a number of supervision studies conducted in supermarkets, ${ }^{8} 5051$ has allowed an understanding of the total context in which unintentional injuries occur. Observational studies of care giver supervision eliminate the possibility of bias and distortion associated with measuring individual's behaviour, which is probable from self report methods. Unfortunately, however, very few observational studies have used multivariate statistical methods to adjust for confounding variables. ${ }^{81}$ Natural observations are very accurate when the researcher specifically defines the parent behaviours to be observed, and develops a way of measuring and quantifying the behaviour, ${ }^{69}$ resulting in maximised ecological validity. ${ }^{7}$ Observing unobtrusively is not problematic in public venues, although there is the ethical dilemma for the observer of deciding when to intervene in a hazardous situation. This method is suited to active sporting and recreational situations, where unintentional injuries are of concern..$^{50}$

\section{IMPLICATIONS FOR PREVENTION}

This systematic review has described the methods that have been used to measure supervision, as well as their advantages and disadvantages. As effective prevention of unintentional childhood injuries is multifaceted, ${ }^{5670}$ a thorough understand ing of supervision, injury risk and the way that these interact can potentially enhance injury prevention understanding.

Several data collection methods have contributed to the area to date; however, the existing evidence is generally of low to moderate methodological quality. This systematic review lends credence to the complex nature of measuring supervision and unintentional injuries in children, and acknowledges that further research using higher quality methods is required to confirm and characterise the risk relationship between super vision and injury. Conducting RCTs is often impractical because of associated ethical issues, but more prospective studies could be undertaken. Nonetheless, there is scope to improve the quality of the research in this area by conducting prospective studies, and the use of mixed method approaches would allow findings to be triangulated. 
The results of this review point to an obvious need for studies to continue to explore the effects of parental supervision on child injury, with the quality of many supervision and child injury risk studies low or moderate. This review paves the way for implementation of higher quality methods, particularly those using valid and reliable measures to improve studies of the relationship between supervision and child injury risk.

Acknowledgements: LP was funded by a University of Ballarat PhD Scholarship. CF was funded by an NHMRC Principal Research Fellowship. Dr Alex Donaldson and Dr Peta White provided comments on a draft version of the paper.

Competing interests: None.

\section{REFERENCES}

1. Australian Institute of Health and Welfare. A picture of Australia's children. Canberra: AlHW, 2005.

2. Finkelstein EA, Corso PS, Miller TR, et al. The incidence and economic burden of injuries in the United States. New York: Oxford University Press, 2006:3 56, 12460.

3. Morrongiello BA, Maclsaac TJ, Klemencic N. Older siblings as supervisors: does this influence young children's risk of unintentional injury? Soc Sci Med 2007:64:807 17.

4. Canadian Institute of Child Health. The health of Canada's children: a CICH profile. 2nd edn. Ottawa: Canadian Institute of Child Health, 1994:41 83.

5. National Centre for Injury Prevention and Control. Centers for Disease Control injury fact book. Atlanta, GA: Centres for Disease Control and Prevention, 2006.

6. Audit Commission and Healthcare Commission. Better safe than sorry: preventing unintentional injury to children. London: Audit Commission Publishing Team, 2007.

7. Morrongiello BA. Caregiver supervision and child injury risk. I. Issues in defining and measuring supervision. II. Findings and directions for future research. J Pediatr Psychol 2005;30:536 52.

8. Harrell WA. Dangerous activities by children in grocery carts: is adult supervision important? Psychol Rep 2003;92:957 62.

9. Morrongiello BA, House K. Measuring parent attributes and supervision behaviors relevant to child injury risk: examining the usefulness of questionnaire measures. Inj Prev 2004;10:114 18

10. Pollack-Nelson C, Drago DA. Supervision of children aged two through six years. Inj Control Saf Promot 2002;9:121 6.

11. Cataldo MF, Finney JW, Richman GS, et al. Behaviour of injured and uninjured children and their parents in a simulated hazardous setting. J Pediatr Psychol 1992;17:73 80 .

12. Morrongiello BA, Dawber T. Toddlers' and mothers' behaviors in an injury risk situation: implications for sex differences in childhood injuries. J Appl Dev Psychol 1998;19:625 39.

13. Roberts I. Parental supervision: a popular myth. Inj Prev 1996;2:9 11.

14. Flavin MP, Dostaler SM, Simpson K, et al. Stages of development and injury patterns in the early years: a population based analysis. BMC Public Health 2006;6:187.

15. Fang $\mathbf{Y}$, Dai $\mathrm{L}$, Jaung MS, et al. Child drowning deaths in Xiamen city and suburbs, People's Republic of China, 2001 5. Inj Prev 2007:13:339 43.

16. Schnake EM, Peterson NM, Corden TL. Promoting childhood water safety: the physician's role. Wisc Med J 2005;104:45 9.

17. Stevenson MR, Rimajova M, Edgecombe D, et al. Childhood drowning: barriers surrounding private swimming pools. Pediatrics 2003;11:115 19

18. DeNicola LK, Falk JL, Swanson ME, et al. Submersion injuries in children and adults. Crit Care Clin 1997;13:477 502.

19. Saluja G, Brenner R, Morrongiello BA, et al. The role of supervision in child injury risk: definition, conceptual and measurement issues. Inj Control Saf Promot 2004;11:17 22.

20. Morrongiello BA, Corbett $M$. The parent supervision attributes profile questionnaire: a measure of supervision relevant to children's risk of unintentional injury. Inj Prev 2006;12:19 23.

21. Mack KA, Sogolow E, Strouse D, et al. The role of supervision of children in injury prevention. Salud Publica Mex 2008:50:112 14

22. Clarke A, Walton WW. Effect of safety packaging on aspirin ingestion by children. Pediatrics 1979;63:687 93.

23. Dowswell T, Towner EML, Simpson G, et al. Preventing childhood unintentional injuries: what works? A literature review. Inj Prev 1996;2:140 9

24. Lawrence DW, Laflamme L. Using online databases to find journal articles on injury prevention and safety promotion research: key journals and databases that index them. Inj Prev 2008;14:91 5.

25. Lawrence DW. Using online databases to find peer reviewed journal articles on injury prevention and safety promotion research: a study of textword queries by SafetyLit users. Inj Prev 2007;13:232 6.

26. Blackhall K, Ker K. Searching for studies for inclusion in Cochrane Systematic Reviews on injury prevention. Inj Prev 2008;14:137 8.

27. Peterson L, Ewigman B, Kivlahan C. Judgments regarding appropriate child supervision to prevent injury: the role of environmental risk and child age. Child Dev 1993;64:934 50

28. National Health and Medical Research Council. A guide to the development, implementation and evaluation of clinical practice guidelines. Canberra: AusInfo, 1999.
29. Finch CF, Kelsall HL. The effectiveness of ski bindings and their professional adjustment for preventing alpine skiing injuries. Sports Med 1998;25:407 16.

30. Morrongiello BA, Hogg K. Mothers' reactions to children misbehaving in ways that can lead to injury: implications for gender differences in children's risk taking and injuries. Sex Roles 2004;50:103 18

31. Iltus SS. Parental ideologies in the home safety management of one to four year old children [PhD dissertation]. New York: The City University, 1994.

32. Wills KE, Christoffell KK, Lavigne JV, et al. Patterns and correlates of supervision in child pedestrian injury. J Pediatr Psychol 1997;22:89 104.

33. Wills KE, Tanz RR, Christoffell KK, et al. Supervision in childhood injury cases: a reliable taxonomy. Accid Anal Prev 1997;29:133 7

34. Morrongiello BA, Midgett C, Shields R. Don't run with scissors: young children's knowledge of home safety rules. J Pediatr Psychol 2001;26:105 15.

35. Garling A, Garling T. Mothers' supervision and perception of young children's risk of unintentional injury in the home. J Pediatr Psychol 1993;18:105 14.

36. Garling A, Garling T. Mothers' anticipation and prevention of unintentional injury to young children in the home. J Pediatr Psychol 1995;20:23 36

37. Morrongiello BA, Corbett M, McCourt M, et al. Understanding unintentional injury risk in young children. I. The nature and scope of caregiver supervision of children at home. J Pediatr Psychol 2006;31:529 39.

38. Morrongiello BA, Ondejko L, Littlejohn A. Understanding toddlers' in home injuries I. Context, correlates, and determinants. J Pediatr Psychol 2004;29:415 31

39. Morrongiello BA, Ondejko L, Littlejohn A. Understanding toddlers' in home injuries. II. Examining parental strategies, and their efficacy, for managing child injury risk. J Pediatr Psychol 2004;29:433 46

40. Smith GA, Bowman MJ, Luria JW, et al. Babywalker related injuries continue despite warning labels and public education. Pediatrics 1997;100:163 7.

41. Bugeja L, Franklin R. Drowning deaths of zero to five year old children in Victorian dams, 1989 2001. Aust J Rural Health 2005;13:300 8.

42. Ross FI, Elliott EJ, Lam LT, et al. Children under 5 years presenting to paediatricians with near drowning. J Paediatr Child Health 2003:39:446 50.

43. Blum C, Shield J. Toddler drowning in domestic swimming pools. Inj Prev 2000;6:28890.

44. Rauchschwalbe R, Brenner RA, Smith GS. The role of bathtub seats and rings in infant drowning deaths. Pediatrics 1997; 100:1 5 .

45. Simon HK, Tamura T, Colton K. Reported level of supervision of young children while in the bathtub. Ambul Pediatr 2003:3:106 8

46. Cass DT, Ross F, Lam LT. Childhood drowning in New South Wales 1990 1995: a population based study. Med J Aust 1996:165:610 12.

47. Kemp AM, Mott AM, Sibert JR. Accidents and child abuse in bathtub submersions Arch Dis Child 1994;70:435 8

48. Jensen LR, Williams SD, Thurman DJ, et al. Submersion injuries in children younger than 5 years. West J Med 1992;157:641 4

49. Harrell WA. Effect of two warning signs on adult supervision and risky activities by children in grocery shopping carts. Psychol Rep 2003:92:889 98

50. Harrell WA. The impact of shopping cart restraints and adult supervision on near injuries to children in grocery stores. Accid Anal Prev 1994;26:493 500.

51. Harrell WA, Reid EE. Safety of children in grocery stores: the impact of cartseat use in shopping carts and parental monitoring. Accid Anal Prev 1990;22:531 42.

52. Landen MG, Bauer U, Kohn M. Inadequate supervision as a cause of injury deaths among young children in Alaska and Louisiana. Pediatrics 2003;111:328 31.

53. Breakwell GM, Hammond S, Fife Schaw C, et al. Research methods in psychology 3rd edn. London: Sage Publications Ltd, 2006:232 72.

54. Jackson SL. Research methods and statistics: a critical thinking approach. 2nd edn Belmont, CA: Thomson Wadsworth, 2006:55 65.

55. Morrongiello BA, Corbett M, McCourt M, et al. Understanding unintentional injury risk in young children. II. The contribution of caregiver supervision, child attributes, and parent attributes. J Pediatr Psychol 2006:31:540 51.

56. Speltz ML, Gonzales N, Sulzbacher S, et al. Assessment of injury risk in young children: a preliminary study of the injury behaviour checklist. J Pediatr Psychol 1990:15:373 83.

57. Thomasgard M, Metz WP, Edelbrock C, et al. Parent child relationship disorders. Part 1. Parental overprotection and the development of the parent protection scale. J Dev Behav Pediatr 1995:16:244 50.

58. Rivara FP, Cummings P, Koepsell TD, et al. Injury control: a guide to research and program evaluation. New York: Cambridge University Press, 2001:89 182.

59. Harrell WA. Does supervision by a lifeguard make a difference in rule violations? Effects of lifeguards' scanning. Psychol Rep 2001;89:327 30.

60. McBurney DJ, White TL. Research methods. 6th edn. Sydney, NSW: Wadsworth/ Thomson Learning, 2004:216 56, 37780

61. Duffy ME. Methodological triangulation: a vehicle for merging quantitative and qualitative research methods. Image J Nurs Sch 1987:19:130 3

62. Hayes N. Doing psychological research. Milton Keynes: Open University Press, 2004:135 6.

63. Dawes M. Randomised controlled trials. In: Dawes M, Davies PT, Gray AM, et al. eds Evidence based practice: a primer for health care professionals. Edinburgh: Harcourt, 2000:49 58

64. Thomas JR, Nelson JK, Silverman SJ. Research methods in physical activity. 5th edn. Champaign, IL: Human Kinetics, 2005:269 84

65. Shaughnessy JJ, Zechmeister EB, Zechmeister JS. Research methods in psychology. 7th edn. New York: McGraw Hill, 2006:143 92.

66. Marczyk G, DeMatteo D, Festinger D. Essentials of research design and methodology. Hoboken, NJ: John Wiley and Sons, Inc, 2005:149 54 
67. Peterson L, Tremblay G. Self monitoring in behavioural medicine: children. Psychol Assess 1999;11:458 65.

68. Brenner RA, Trumble AC, Smith GS, et al. Where children drown, United States, 1995. Pediatrics 2001;108:85 9
69. Berg KE, Latin RW. Essentials of research methods in health, physical education, exercise science, and research. 2nd edn. Baltimore: Lippincott Williams \& Wilkins, 2004:197 223.

70. National Public Health Partnership. The national injury prevention and safety promotion plan: 2004 2014. Canberra: NPHP, 2004. 